\title{
A Coherent and Integrated Framework Using Concept Maps for Various Educational Assessment Functions
}

\author{
Evangelia Gouli, Agoritsa Gogoulou, and Maria Grigoriadou \\ University of Athens, Greece
}

\section{lilag@di.uoa.gr rgog@di.uoa.gr gregor@di.uoa.gr \\ Executive Summary}

Educational assessment is a process of drawing reasonable inferences about what students know on the basis of evidence derived from observation of what they say, do or make in selected situations. Educational assessment does not exist in isolation, but should be aligned with instruction in order to support and enhance learning. Assessment functions may be varied, ranging from a need to identify the students' prior knowledge to a need to draw conclusions about their overall understanding of the subject matter.

In this paper, a coherent and integrated framework for educational assessment purposes, serving various assessment functions, is presented. The framework named AssessToLearn uses concept maps as the main tool of the assessment toolbox and provides a basis for the design of assessment activities following a three-step process (i) Ascertaining the Students' Prior Knowledge - Activating Knowledge, (ii) Promoting Knowledge Construction \& Identifying Conceptual Changes - Constructing \& Enriching Knowledge, and (iii) Assessing Knowledge Construction - Refining Knowledge. The assessment functions of each step are accomplished through assessment activities, which may include one or more subactivities and/or assessment items addressing specific assessment outcomes. The assessment items may be implemented by employing various concept mapping tasks such as the "free construction"/the "concept list"/the "partial recall framework"/the "partial recognition framework" tasks, or utilizing other assessment tools such as various types of questions like free-response questions, questions based on short cases, multiple-choice questions, and true/false questions. The AssessToLearn framework constitutes the basis for the development of a web-based adaptive assessment environment, referred to as PASS (Per-

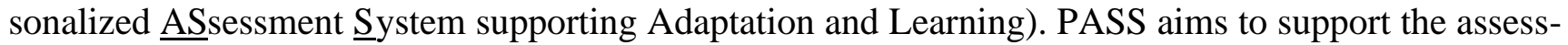
ment process in the context of the framework and provide adaptive capabilities as far as the adaptation of the assessment process and the guidance/feedback given to the students during the assessment process are concerned.

For the application and evaluation of the proposed framework in a real classroom environment, an experimental study was conducted. The study was carried out in the context of the postgraduate course of "Distance Education and Learning" at the Department of Informatics and Telecommunications of the University of Athens during the spring-semester of the academic year 2001-2002. Based on the framework, a set of assessment activities was developed, aiming to serve the following assessment functions:

Material published as part of this journal, either on-line or in print, is copyrighted by the publisher of the Journal of Information Technology Education. Permission to make digital or paper copy of part or all of these works for personal or classroom use is granted without fee provided that the copies are not made or distributed for profit or commercial advantage AND that copies 1) bear this notice in full and 2) give the full citation on the first page. It is permissible to abstract these works so long as credit is given. To copy in all other cases or to republish or to post on a server or to redistribute to lists requires specific permission and payment of a fee. Contact Editor@ JITE.org to request redistribution permission. (i) identification of the students' prior knowledge,

(ii) investigation/identification of the students' unknown concepts, incomplete understanding and false beliefs, (iii) assessment of the conceptual changes and growth in the students' understanding during, as well as at the end of the teaching and the learning processes, and (iv) assessment of the students' overall understanding of the subject matter. The experimental results are encouraging, indicating the effectiveness of the assessment ac- 
tivities and subsequently the effectiveness of the framework in serving the assessment functions under consideration.

More specifically, as far as the first step of the framework is concerned, the context of the assessment activity and the use of the concept maps as the main assessment tool contributed effectively to "ascertain what the students already know" including faulty and/or incomplete knowledge structures. The scaffolding framework of the free response questions and the questions based on short cases, helped the students in activating their knowledge while the "free-construction/concept list" task proved to be the most effective of the alternative ones, as it enabled the students to represent their knowledge on their own and then to enrich and revise their representations. Regarding the second step of the framework, the assessment activity was based on the idea of the goal-based scenarios where the students played the role of the tutor according to a given scenario and assessed the coursework (i.e. the concept map) of a (fictional) learner. The scenario operations, and especially those concerning the assessment of the concept map, enabled the identification and the assessment of the students' progressive conceptual changes concerning the fundamental concepts of the subject matter. The context of the activity helped the students to gain deeper understanding of the subject matter but contributed, to a low degree, to the development of high level cognitive skills such as analysis and synthesis. Moreover, the authentic context of the activity engaged the students actively in the learning process and supported the development of skills concerning reasoned judgment, reflection, revision and critical thinking. The assessment activity, concerning the third step, was comprised of a concept mapping task and an evaluation task. The students had to construct, on their own from scratch, a concept map concerning the central concept of the subject matter. Upon the completion of the concept mapping task, the students had to evaluate their own concept maps by determining evaluation criteria, scoring their map for each criterion and reasoning their evaluation. The use of concepts maps in the context of the assessment activity, proved to be a viable alternative tool to the "traditional final exams," enabling the drawing of inferences about the students' overall understanding of the subject matter, the detection of changes in the students' conceptual understanding, the identification of differences in the students' abilities and the determination of key-points that may be used in order to differentiate the students' knowledge level concerning the subject matter. Also, the evaluation task in the context of the activity gave the students the chance to become active participants in their own learning and to refine further their knowledge by evaluating their own work.

Keywords: Educational Assessment, Assessment Framework, Assessment Functions, Assessment Activities, Concept Maps, Prior Knowledge, Conceptual Changes, Knowledge Construction.

\section{Introduction}

Educational assessment is a process of drawing reasonable inferences about what students know on the basis of evidence derived from observation of what they say, do or make in selected situations (Pellegrino, Chudowsky, \& Glaser, 2001). Educational assessment helps students to identify what they have already learned, to observe their personal learning progress and to decide how to further direct their learning process. On the other hand, teachers can exploit the assessment results in the direction of giving appropriate feedback and support to the students during the instruction, formulating judgements about the quality and the effectiveness of the provided educational material and modifying the curriculum, their instruction and their teaching practices/strategies.

During the design of the assessment process, the teacher has to decide and determine basic elements of the assessment process, such as the purpose (i.e. formative assessment or summative assessment), the duration, the educational and the assessment goals, the educational resources that are necessary to support the assessment process and the assessment tools. The determination of these elements depends on various factors such as the diversity of learning theories, the diversity in what counts as evidence of learning, the teaching strategies that are followed, the number of students and the constraints of the educational setting, such as the cost. A variety of assessment tools may be employed in order to integrate 
the assessment process with the ongoing instruction, to document the students' growth, and to identify changes in their thinking and learning skills, such as various types of questions (e.g. free-response questions, questions based on short cases, etc) and concept mapping tasks. Each of these assessment tools has specific characteristics and may serve various assessment functions. Concept maps are considered to be a valuable tool of an assessment toolbox, as they provide an explicit and overt representation of the students' knowledge and promote meaningful learning (Mintzes, Wandersee, \& Novak, 2000; Novak \& Gowin, 1984; Novak, 1998). As reported in Pearsall, Skipper, and Mintzes (1997), concept maps "provide a unique window into the way learners structure their knowledge, offering an opportunity to assess both the propositional validity and the structural complexity of that knowledge base."

In this paper, we propose a coherent and integrated framework for educational assessment purposes serving various assessment functions, ranging from a need to identify the students' prior knowledge to a need to draw conclusions about their overall understanding of the subject matter. The AssessToLearn framework provides a basis for the design of assessment activities incorporating principles from contemporary theories of learning and uses concept maps as the main tool of its assessment toolbox. It comprises a three-step process consisting of (i) Ascertaining the Students' Prior Knowledge - Activating Knowledge, (ii) Promoting Knowledge Construction \& Identifying Conceptual Changes - Constructing \& Enriching Knowledge, and (iii) Assessing Knowledge Construction - Refining Knowledge. The AssessToLearn framework constitutes the basis for the development of a web-based adaptive assessment

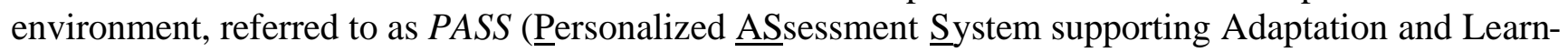
ing). PASS aims to support the assessment process in the context of the framework and provide adaptive capabilities as far as the adaptation of the assessment process and the guidance/feedback given to the students during the assessment process are concerned.

For the application and evaluation of the proposed assessment framework in a real classroom environment, an experimental study was conducted. The study was carried out in the context of the postgraduate course of "Distance Education and Learning" at the Department of Informatics and Telecommunications of the University of Athens during the spring-semester of the academic year 2001-2002. More specifically, a set of assessment activities were developed on the basis of the framework, aiming to serve the following assessment functions: (i) identification of the students' prior knowledge, (ii) investigation/identification of the students' unknown concepts, incomplete understanding and false beliefs, (iii) assessment of the conceptual changes and the growth in the students' conceptual understanding during, as well as at the end of the teaching and the learning processes, and (iv) assessment of the students' overall understanding of the subject matter.

The paper is organized as follows. In the next section, a brief presentation of the concept maps, focusing on their use for educational purposes, is given. Then, the proposed assessment framework and its threestep process are presented. Following that, issues concerning the adoption/support of the framework in the PASS environment are discussed, providing a brief presentation of its main functionality. Afterwards, we give a detailed description of the experimental study presenting how each step of the framework was applied, what kind of activities were developed, and the evaluation results concerning the effectiveness of the assessment activities to support the assessment functions under consideration. The paper ends with the concluding remarks and our future plans.

\section{Background Issues Concerning Concept Maps}

A concept map is a graphical node-arc representation, where nodes represent concepts and labelled arcs or lines represent the relationships between concepts (Novak \& Gowin, 1984). Concept maps provide a means to capture, elicit and represent qualitative aspects of the students' knowledge. In its simplest form, a concept map is composed of just two concepts connected by a linking word to form a single proposition. For example, "Distance Education is a tool for Open Education" represents a simple concept map forming a valid proposition about the concepts "Distance Education" and "Open Education". 
Three characteristics of the concept maps are: (i) their hierarchical structure (with the most inclusive, most general concepts at the top of the map and the more specific, less general concepts arranged hierarchically below), (ii) the inclusion of "cross-links" relating domains of knowledge represented on the map and indicating "the integrative reconciliation of meanings" (Novak \& Gowin, 1984), and (iii) the inclusion of examples clarifying the meaning of a given concept.

Concept mapping - the process of organizing concepts in a hierarchical manner and forming meaningful relationships between the concepts - has grown out of Ausubel's theory of meaningful versus rote learning (Ausubel, Novak, \& Hanesian, 1978). The theoretical framework that supports the use of concept mapping is consistent with constructivist epistemology and cognitive psychology (Edmondson, 2000). Concept mapping tasks vary as to whether concepts and/or labels for the relationships between concepts are given to the students for mapping or the students are responsible for the whole process. Also, concept mapping tasks vary as to whether a structure of the map is given and the students fill in the nodes and/or the links, or the students construct the map on their own from scratch. The traditional way of constructing concept maps uses paper and pencil. With the rapid development of Information and Communication Technologies (ICT), a number of computer-assisted concept mapping systems have been proposed (Chang, Chen, \& Sung, 2001; Fisher, 2000) and nowadays, internet-based concept mapping systems are available (Chiu, Huang, \& Chang, 2000; Tsai, Lin, \& Yuan, 2001).

\section{Educational Purposes of Concept Mapping}

Concept maps can be used for a variety of educational purposes or functions (Jonassen, Reeves, Hong, Harvey, \& Peters, 1997; Novak, 1990). They have been successfully used in many disciplines, particularly in science, as an instructional tool, as a tool to promote meaningful learning, as an assessment tool, and as a curriculum organization guide in teaching (Mintzes et al., 2000; Trowbridge \& Wandersee, 1998). As an instructional tool, concept maps may be used by the teacher for the organization of the course content and/or the presentation of the educational material to the students.

Concept maps, as a learning tool, can serve as a facilitator for helping students to learn, to create and to use knowledge (Novak, 1998). The concept mapping process (i) promotes and assists meaningful learning (Fisher, Faletti, Patterson, Thornton, Lipson, \& Spring, 1990; Novak, 1998, 1990) by encouraging students to identify concept meanings, to establish their own relationships between concepts, to rearrange the existing relationships, to relate new concepts to prior concepts, to organize the concepts in a hierarchical and integrated manner and to refine the completed map resulting in generalized schemata for certain concepts, (ii) helps students to organize knowledge in meaningful related chunks (Novak, 1998), promoting better knowledge organization in memory, better retention, retrieval and application of knowledge in new situations, and (iii) helps students to realize that learning requires their active and constructive involvement, to understand better the content and the process of effective, meaningful learning (Edmondson, 2000) and to "learn how to learn" by bringing to the surface cognitive structures and self-constructed knowledge (Novak \& Gowin, 1984).

Concept maps, as an assessment tool, can reveal to both students and teachers the quality and the level of development of conceptual understanding for any domain and at any grade level (Novak, 1998). In their early work, Novak and Gowin (1984) found that concept maps gave teachers and researchers more accurate and more authentic insights into the students' thinking than traditional methods of testing. Also, as mentioned in Fisher, Wandersee, and Wideman (2000), the concept map provides a better gauge of what students know than most other assessments tools because it allows free response and it provides insights into the students' knowledge structure. Moreover, according to Novak and Musonda (1991), it has been found that "concept maps are not only reliable and valid but also measure aptitudes not commonly assessed by typical objective tests." 
A lot of research studies of different-aged and culturally diverse students have been conducted and have shown the positive effects of concept mapping on the students' meaningful learning and on knowledge attainment, especially for the learning of science concepts (Horton, McConney, Gallo, Woods, Senn, \& Hamelin, 1993; Novak, 1990, 1998). Moreover, growing research evidence points to the utilization of concept maps as assessment tools, and a number of research studies have been conducted on the schemes that can be used for scoring concept maps and on the validity and reliability of concept maps for summative and large-scale assessment approaches (Markham, Mintzes, \& Jones, 1994; Mintzes et al., 2000; Rice, Ryan, \& Samson, 1998; Ruiz-Primo \& Shavelson, 1996; Ruiz-Primo, Shavelson, \& Schultz, 1997; Shavelson, Lang, \& Lewin, 1994).

\section{The AssessToLearn Framework}

Regarding the assessment of student learning as an integral and essential part of the processes of teaching and learning, and the concept maps as a valuable assessment tool promoting the meaningful learning and contributing to the knowledge construction process, we propose a coherent and integrated framework in the educational assessment process, referred to as AssessToLearn.

The AssessToLearn framework consists of a three-step process incorporating principles from contemporary theories of learning. Each step addresses specific assessment functions and serves specific assessment purposes, which are presented in Table 1. The assessment functions and, subsequently, the assessment purposes are accomplished through assessment activities, which may include one or more subactivities and/or assessment items addressing specific assessment outcomes. Considering concept maps as the main tool of the assessment toolbox, the assessment items may be implemented by employing various concept mapping tasks such as (i) the construction of a concept map from scratch ("free construction" task), and/or using an available list of concepts ("concept list" task), and/or (ii) fill some blanks concerning concepts/relationships ("partial recall framework" task) (Tsai et al., 2001), and/or fill some blanks concerning concepts/relationships by using an available list ("partial recognition framework" task) (Tsai et al., 2001). Furthermore, the assessment activity may be accompanied by additional assessment items utilizing other assessment tools with various types of questions, such as free-response questions, questions based on short cases (Segers, Dochy, \& De Corte, 1999), multiple-choice questions, and true/false questions. Table 2 depicts the assessment tools as well as the forms of assessment that may be applied in each step of the framework. Following are detailed descriptions of the three steps of the AssessToLearn framework.

\section{Step 1: Ascertaining the Students' Prior Knowledge - Activating Knowledge}

According to the contemporary view of learning, prior knowledge is a major variable, as it may greatly hinder or facilitate the learning process. The students construct new knowledge and understandings on the basis of what they already know and believe (Bransford, Brown, \& Cocking, 1999; Vosniadou, 2001). It is very difficult and/or impossible for the students to understand, remember and/or learn concepts that are completely unfamiliar. Moreover, it is not sufficient for the students just to have the prerequisite prior knowledge; it is necessary to activate this knowledge. In the epigraph to Educational Psychology: A Cognitive View, David Ausubel (1978) says "If I had to reduce all of educational psychology to just one principle, I would say this: The most important single factor influencing learning is what the learner already knows. Ascertain this and teach him accordingly." The ascertainment of the students' prior knowledge may contribute to (i) the determination of the teaching/instruction's framework, taking into account the students' initial beliefs, and (ii) the development of an appropriate scaffolding framework, which can guide/support the students in the development of effective mental models. 


\begin{tabular}{|c|c|c|c|}
\hline \multicolumn{4}{|c|}{ The AssessToLearn Framework: The Assessment Purposes \& The Assessment Functions } \\
\hline \multirow[b]{2}{*}{$\begin{array}{l}1^{\text {st }} \\
\text { step }\end{array}$} & Purpose & $\begin{array}{l}\text { Ascertaining the Students' Prior Knowledge } \\
\text { The assessment activity aims to enable } \\
\text { the teachers to ... }\end{array}$ & $\begin{array}{c}\text { Activating Knowledge } \\
\text { The assessment activity aims to } \\
\text { enable the students to ... }\end{array}$ \\
\hline & \multirow{3}{*}{$\begin{array}{l}\text { Formative Assessment } \\
\text { or } \\
\text { Assessment to assist } \\
\text { learning }\end{array}$} & $\begin{array}{l}\text { (i) elicit the students' prior knowledge, } \\
\text { (ii) identify the students' initial performance } \\
\text { level (knowledge and skills) as far as the new } \\
\text { concepts are concerned, and } \\
\text { (iii) diagnose the students' unknown concepts, } \\
\text { incomplete understanding, false beliefs and na- } \\
\text { ive renditions of the concepts under considera- } \\
\text { tion. }\end{array}$ & $\begin{array}{l}\text { activate their existing knowl- } \\
\text { edge. }\end{array}$ \\
\hline \multirow[b]{2}{*}{$\begin{array}{l}2^{\text {nd }} \\
\text { step }\end{array}$} & & $\begin{array}{c}\text { Promoting Knowledge Construction \& } \\
\text { Identifying Conceptual Changes } \\
\text { The assessment activity aims to enable } \\
\text { the teachers to ... }\end{array}$ & $\begin{array}{l}\text { Constructing \& Enriching } \\
\text { Knowledge } \\
\text { The assessment activity aims to } \\
\text { enable the students to ... }\end{array}$ \\
\hline & & $\begin{array}{l}\text { (i) promote the students' knowledge construc- } \\
\text { tion (provision of feedback, support of collabo- } \\
\text { ration, support of exploratory learning, etc), } \\
\text { (ii) promote the development of high level cog- } \\
\text { nitive skills such as reflection, revision, critical } \\
\text { thinking and self-regulation, } \\
\text { (iii) monitor/assess the students' progressive } \\
\text { changes during the instruction, and } \\
\text { (iv) encourage the active involvement of the } \\
\text { students in the knowledge construction process. }\end{array}$ & $\begin{array}{l}\text { monitor how their learning } \\
\text { progresses, and whether their } \\
\text { knowledge is revised and/or } \\
\text { enriched with and incorporates } \\
\text { effectively new knowledge. }\end{array}$ \\
\hline \multirow[b]{2}{*}{$\begin{array}{l}3^{\text {rd }} \\
\text { step }\end{array}$} & \multirow{2}{*}{$\begin{array}{l}\begin{array}{l}\text { Summative Assessment } \\
\text { or Assessment of indi- } \\
\text { vidual achievement }\end{array} \\
\text { (it assesses the quantity } \\
\text { and retention of learn- } \\
\text { ing following the com- } \\
\text { pletion of a unit of in- } \\
\text { struction (Kommers et } \\
\text { al., 1996; Pellegrino et } \\
\text { al., 2001)) }\end{array}$} & $\begin{array}{c}\text { Assessing Knowledge Construction } \\
\text { The assessment activity aims to enable } \\
\text { the teachers to ... }\end{array}$ & $\begin{array}{c}\text { Refining Knowledge } \\
\text { The assessment activity aims to } \\
\text { enable the students to ... }\end{array}$ \\
\hline & & $\begin{array}{l}\text { (i) capture the growth in the students' overall } \\
\text { conceptual understanding, and } \\
\text { (ii) identify how the students' knowledge has } \\
\text { been constructed after the completion of the } \\
\text { instruction. }\end{array}$ & $\begin{array}{l}\text { (i) refine their knowledge } \\
\text { (promotion of high level cogni- } \\
\text { tive skills such as critical think- } \\
\text { ing and reasoned judgment), } \\
\text { and } \\
\text { (ii) draw conclusions about the } \\
\text { degree of achieving the ex- } \\
\text { pected learning outcomes. }\end{array}$ \\
\hline
\end{tabular}

Table 1: The three steps of the framework serving various assessment functions

The assessment activities, utilising concept maps, may include assessment items employing the aforementioned concept mapping tasks. For example, an assessment activity may include a "freeconstruction" task, asking the students to construct a map concerning a particular central concept either from scratch or after studying a relevant text. This task may activate the students' prior knowledge and reveal their false beliefs, and may also show the students' initial degree of understanding concerning concepts of the subject matter included in the text and their ability to perceive and represent the most important information. During the process of concept mapping, the teacher may guide the students through a scaffolding framework. The scaffolding framework may include a set of questions, relevant comments, hints, etc, aiming to relate new concepts to the students' experience and prior knowledge and show aspects of the meaning of the concepts under consideration. Apart from concept mapping tasks, the designed assessment activities may include assessment items like (i) true/false questions and/or multiple-choice questions asking the students to recognize/identify the definition of a concept, (ii) free response questions asking the students to compare two concepts, (iii) questions based on short cases asking the students to distinguish important from unimportant concepts mentioned in the given short case, 


\begin{tabular}{|c|c|c|c|}
\hline & \multicolumn{2}{|c|}{ Assessment Tools } & Forms of Assessment \\
\hline $1^{\text {st }}$ step & $\begin{array}{l}\text { Various concept mapping } \\
\text { tasks } \\
\text { such as } \\
\text { "free construction" task }\end{array}$ & $\begin{array}{l}\text { Various types of } \\
\text { questions such as }\end{array}$ & $\begin{array}{l}\text { collaborative assessment following alterna- } \\
\text { tive models of collaboration between the } \\
\text { group members } \\
\text { self-assessment (activating and assessing one- } \\
\text { self's prior knowledge) }\end{array}$ \\
\hline $2^{\text {nd }}$ step & $\begin{array}{l}\text { "concept list" task } \\
\text { (using an available list of } \\
\text { concepts) } \\
\text { "partial recall framework" } \\
\text { task } \\
\text { (fill some blanks concerning } \\
\text { concepts/relationships) }\end{array}$ & $\begin{array}{l}\text { free-response ques- } \\
\text { tions } \\
\text { questions based on } \\
\text { short cases } \\
\text { multiple choice } \\
\text { questions } \\
\text { true/false questions }\end{array}$ & $\begin{array}{l}\text { collaborative assessment following alterna- } \\
\text { tive models of collaboration between the } \\
\text { group members } \\
\text { self - assessment (assess and monitor one- } \\
\text { self' s learning progress on the content that } \\
\text { the student has already studied/learned) } \\
\text { peer - assessment (assess other students' } \\
\text { work) }\end{array}$ \\
\hline $3^{\text {rd }}$ step & $\begin{array}{l}\text { "partial recognition frame- } \\
\text { work" task (fill some blanks } \\
\text { concerning con- } \\
\text { cepts/relationships by using } \\
\text { an available list) }\end{array}$ & $\begin{array}{l}\text { ordering questions } \\
\text { fill-in-the-blank } \\
\text { questions }\end{array}$ & $\begin{array}{l}\text { summative assessment on the overall content } \\
\text { peer - assessment (assess other students' } \\
\text { work) } \\
\text { self - assessment (assess oneself' s own } \\
\text { work) }\end{array}$ \\
\hline
\end{tabular}

Table 2: The assessment tools and the forms of the assessment that may be applied in each step of the framework

etc. Moreover, the students may collaborate in pairs acting equivalently, allowing the ascertainment of each of the student's prior knowledge.

\section{Step 2: Promoting Knowledge Construction \& Identifying Conceptual Changes - Constructing \& Enriching Knowledge}

During instruction, it is essential for the teacher to draw inferences about the students' level of comprehension of the new concepts and the skills they are developing as well as to involve the students actively in the learning process. This can be achieved by establishing an assessment environment that is challenging and interesting to the students and promotes their active participation and the development of skills such as critical thinking, revision, reflection, and self-regulation (Kordaki \& Avouris, 2002; Vosniadou, 2001). Sometimes, the students are not willing to perform an assessment activity because they understand neither why they are doing it nor what its purpose and usefulness is. Teachers can make assessment activities more meaningful by situating them in an authentic context (Vosniadou, 2001).

The assessment activities may combine concept mapping tasks with alternative teaching/educational techniques, such as goal-based scenarios (Schank, Berman, \& Macpherson, 1999), case studies, and role-playing. The concept mapping tasks may ask the students to construct a map concerning an already taught concept and/or to evaluate a concept map. For example, the assessment activities may ask the students (i) to construct a map concerning an already taught concept following either the "freeconstruction" or the "concept-list" task, and/or (ii) to enrich a given concept map with a number of concepts, which may result after the study of a text and/or the search for relevant information from the Web, and/or (iii) to check the correctness of a number of given propositions, to reason their judgement, and to correct them appropriately, and/or (iv) to evaluate a concept map according to pre-specified given criteria, and/or (v) to act as evaluators of other students' concept maps and to give them the appropriate feedback in order to improve their work. Besides, the students may collaborate in the context of the assessment activity, developing further their skills for self-monitoring, self-control, critical thinking and reasoning. The students' involvement in collaborative assessment activities may enhance the learning since they are forced to externalise/negotiate on their thoughts/ideas, to provide sound argumentation on their actions or on their 
points of view and to articulate their reasoning (Vosniadou, 2001). For example, the students may collaborate in pairs either acting equivalently or by undertaking a specific role at different stages of the assessment activity, e.g. one student may act as the "creator" of the concept map and the other as its "evaluator", or they may construct their own maps and afterwards discuss their maps and proceed with their join, or they may construct a concept map according to specific scenarios of interaction, or they may act as "evaluators" assessing in common a map of a fictional student, etc.

\section{Step 3: Assessing Knowledge Construction - Refining Knowledge}

Completing the teaching and the learning process, both the teacher and the students need to know the degree of achieving the expected learning outcomes and assess the models that the students constructed. The final step aims to assess the students' overall knowledge construction and to enable the refinement of the students' knowledge. Usually, this stage of assessment is carried out through the form of exams where the students have to answer a series of various types of questions (free response, multiple choice, etc) or to solve exercises in a limited time. This process, on the one hand, complicates the teachers in drawing direct conclusions about the students' conceptual changes and the degree of performance and on the other hand, does not enable the students to refine their knowledge.

The assessment activities serving this step may combine concept mapping tasks with additional tasks revealing the students' understanding of the taught concepts (e.g. whether they are able to distinguish the most important concepts), the skills that the students developed during the learning process (e.g. whether they are able to reason their arguments, to design and apply evaluation criteria and give appropriate feedback when they act as peer evaluators of other students' work), etc. For example, the students may be engaged in an assessment activity concerning the construction of a map about the central concept of the subject matter combined with an evaluation task asking them to assess their own map. During this step, it is better not to let students collaborate in order to examine each student's performance/conceptual changes and to determine the degree that each student was influenced by any collaborative assessment activity that s/he participated in during the previous steps.

Although, there is an inherent ordering among these three steps, the ordering does not preclude cycles. Taking into account the incremental nature of knowledge construction and according to the complexity of the taught content, several cycles through various combinations of the steps may be performed. For example, following the second step, the first step may be repeated for new concepts and/or the second step may be repeated for several times. Moreover, the steps of the framework may be applied independently or may be combined in different ways according to the assessment functions to be served.

\section{The Personalized ASsessment System Supporting Adaptation and Learning}

The AssessToLearn framework serves various assessment functions and implies the use of specific assessment tools and assessment forms to be followed in each one of the three steps. The development of a web-based adaptive environment to support the assessment process in the context of the AssessToLearn framework requires the examination and specification of issues regarding the support and implementation of (i) the addressed assessment functions and subsequently the designed assessment activities, (ii) the required assessment tools to enable the elaboration and the accomplishment of the assessment activities, and (iii) the forms of assessment that may be followed during the assessment process. Towards the direction of developing a web-based adaptive assessment environment, referred to as PASS (Personal-

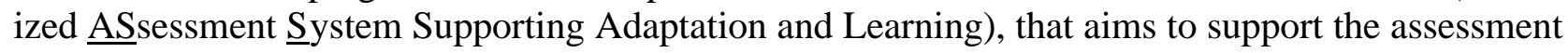
process in the context of the framework and provide adaptive capabilities as far as the adaptation of the process and the guidance/feedback given to the students during the assessment process are concerned, we examine and discuss the aforementioned issues. 
The assessment functions are accomplished through assessment activities, which may include one or more sub-activities and/or assessment items. In the context of a specific subject matter, the assessment activity may concern one or more fundamental concepts (which constitute a fundamental topic) of the knowledge domain of the subject matter and address a specific assessment goal, which is further analyzed in specific assessment outcomes. The assessment outcomes, which are a means of measurement, may address the Comprehension level, Application level, Checking-Critiquing level, and Creation level (Gouli, Gogoulou, Grigoriadou, \& Samarakou, 2003a). For example, as far as the subject matter of "Distance Education and Learning" is concerned (i.e. the subject matter of the study), an assessment goal may be "Do I know the concept of 'Open \& Distance Education",', which may be further analyzed in the assessment outcomes "enumerate and identify the main characteristics of the 'Distance Education", "mention the main models of 'Distance Education"”, "relate the concepts of 'Distance Education' and 'Open Education"” and so forth (concerning the Comprehension level), and assessed through a set of assessment activities/sub-activities/assessment items. For example, an assessment activity may include (i) one sub-activity, consisting of two assessment items addressing the first two assessment outcomes respectively and employing as assessment tools the free-response questions, and (ii) one sub-activity addressing the third assessment outcome and employing the "partial recall framework" concept mapping task.

Each assessment activity (or sub-activity) may include a number of assessment items, which imply the use of different assessment tools, such as concept mapping tasks and/or various types of questions. Therefore, it is necessary to provide the appropriate means in order to enable the employment of various alternative assessment tools. In the case of concept mapping tasks, we develop a web-based concept mapping tool, called COMPASS (으cept $\underline{\mathrm{M}} \underline{\mathrm{P}} \underline{\mathrm{ASS}} \underline{\underline{\mathrm{C}}}$. complish the aforementioned concept mapping tasks. The COMPASS tool supports the automatic interpretation of the students' concept maps based on their similarity to the experts' concept maps and their automatic assessment according to criteria (e.g. number of concepts, number of correct links, number of cross-links etc) specified by the experts. In the case of the other assessment tools, we develop a webbased question module, called WQUEST (Web QUESTion assessment module), which constitutes one of the main modules of the PASS environment. WQUEST enables the elaboration and the accomplishment of assessment items having the form of multiple-choice questions, ordering questions, true-false questions, free-response/short answer questions, questions based on short cases, fill-in-the-blank questions, and so forth. The automatic assessment of the students' responses is supported in all the forms of questions except the free-response/short answer questions, which may be assessed by the tutor and/or by the peers.

Concerning the form of the assessment (i.e. collaborative assessment, peer assessment, self-assessment, summative assessment) that may be followed, the PASS environment supports the self-assessment and/or the summative assessment, providing to the students all the necessary facilities (e.g. submission of assessment activities, access to educational material) in order to enable them to assess their own work and their learning progress during the instruction and to have access to the appropriate feedback material. In the case of the collaborative assessment, the PASS environment activates the SCALE environ-

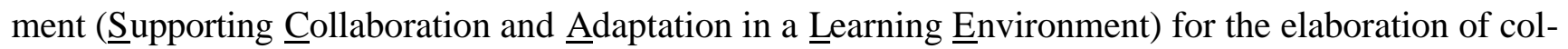
laborative assessment activities. SCALE (Gogoulou, Gouli, Grigoriadou, \& Samarakou, 2003) is a webbased synchronous collaborative environment, which enables the students to work on collaborative assessment activities concerning various subject matters of different orientation, guides and helps the students through intelligent agents, supports alternative models of collaboration between the group members, and improves the collaboration/communication by adapting the "communication-scaffolding" tools (i.e. sentence openers and communication acts) according to the assessment outcomes addressed by the assessment activity and/or the model of collaboration. Depending on the assessment function to be served and the context of the assessment activity (i.e. the assessment outcomes and the assessment tool, 
which is used), the students may collaborate in groups (up to four members) according to specific roles. For example, in cases of groups consisting of four members, different roles may be assigned to the group members, such as the role of "clarifier"(i.e. someone who tries to explain what someone says in order to make sure that everyone understands), the role of "questioner" (i.e. someone who asks questions and stimulates the discussion), the role of "devil's advocate" (i.e. someone who argues against ideas) and the role of "responder" (i.e. someone who proposes alternative solutions, gives clarifications, answers to questions). In the case of peer-assessment, the PASS environment activates the NETPEASE environment (NETwork PEer ASsessment Environment), which is a web-based peer assessment environment, aiming to (i) enable the students to upload their assessment activities (usually addressing outcomes of the Creation level), (ii) assess the work of other students according to pre-specified criteria or according to criteria determined by the students, and (iii) provide feedback to their peers about their work.

During the elaboration of an assessment activity (sub-activity and/or assessment item), the PASS environment provides to the students different types of guidance/feedback. The feedback module, supported by the PASS environment, helps the students to find the correct answer and subsequently to learn through the different types of feedback, and to obtain and record information about the students' preferences, their motivation and their willingness to learn (e.g. whether they prefer to see the correct solution or to review the relevant material in order to find the solution). Indicative types of feedback that are supported by PASS are: (i) the corrective feedback, which informs the students about the correctness/incorrectness of their answer, (ii) the suggestive feedback, which informs the students about the incompleteness of their answers in the form of hints, content-related questions and/or providing new information (Chi, 1996), (iii) elaborated feedback, which provides an explanation for the correctness/incorrectness of the response, or allows the student to review material relevant to the correct response (Hsieh \& O’Neil, 2002), and (iv) holistic feedback, which provides general guidelines.

Also, the PASS environment enhances the assessment process with adaptive capabilities in order to make the whole process dynamic, individualized, meaningful and less tedious for the students. More specifically, the number of the assessment activities/assessment items suggested by PASS as well as the level of their difficulty and the level of their assessment outcomes are adapted according to each student's performance. For example, for a novice student, assessment activities addressing mainly the Comprehension level (i.e. low level cognitive processes/skills) of the assessment outcomes are suggested by PASS. In case that the students are not able to answer multiple choice and/or free response questions, then questions based on short cases may be proposed, aiming, through the provided scaffolding framework, to activate the students' knowledge, to introduce/remind them the meaning of new/already known concepts and to help them to determine more correctly and precisely the context of the concepts under consideration. Also, if the students have little experience in constructing concept maps from scratch, activities utilizing the "partial recall" and/or the "partial recognition framework" tasks may be initially proposed. The adaptive questions and/or the adaptive testing techniques are used to support the adaptivity of the assessment process (Gouli, Papanikolaou, \& Grigoriadou, 2002).

PASS is in the initial phase of development. Currently, we are finishing the implementation of the COMPASS tool, the modules/interface for the assessment activity presentation and the basic modules of the SCALE environment, responsible for the group communication.

\section{The Experimental Study}

\section{The Context of the Study}

During the spring-semester of the academic year 2001-2002 and in the context of the postgraduate course of "Distance Education and Learning" at the Department of Informatics and Telecommunications of the University of Athens, we applied and evaluated the proposed framework. The content of the 
course addresses the following subjects: (i) Open and Distance Learning (ODL) and Open and Distance Educational Systems, (ii) the role of the tutor in ODL, (iii) the design and implementation of educational material suitable for ODL, and (iv) the exploitation of ICT in ODL. As the course progresses, the students are expected to gain a deep understanding of the concepts under discussion and their interrelationships. The lesson is carried out three hours per week in the traditional way, i.e. "face to face teaching".

In the context of the course, with interweaving assessment and instruction in order to improve education and enhance learning as an objective, we applied the proposed framework and we used concepts maps as the main assessment tool. More specifically, in the context of an experimental study, we developed and experimentally evaluated a set of assessment activities following the three-step process of the AssessToLearn framework. A total of 51 postgraduate students participated in the three-step assessment process. The students' backgrounds were diverse, ranging from teachers at the secondary education to system managers and software engineers.

During the course, the instruction was supported by a web-based course-management system, called EClassroom (http://hermes.di.uoa.gr/pms542). The E-Classroom environment offers several facilities to the students and the instructor. In particular, the system provides a number of facilities to the students, such as access to the educational material and to the course announcements, submission of their course assignments and their assessment tests, participation in discussion forums, and access to other students' work. Registration and course authorization tools are also available. The instructor may add specific course content and release appropriate educational materials, assessments tests, assignments and announcements and may have access to various statistics reports showing the number of times and the date on which each student accesses course content, assessment tests and assignments. For the accomplishment of the assessment activities of the study, the students had at their disposal all the necessary educational tools that were necessary (e.g. the Inspiration tool (http://www.inspiration.com) was used for the construction of the concept maps).

At the beginning of the course, two hours training was devoted to concept maps in order for the students to become familiar with the use of concept maps, their role, their advantages and the operational definitions of terms, such as concepts, propositions, relationships, hierarchy, cross-links and examples. During the training, the students constructed simple concept maps with paper and pencil. Moreover, about ten to twenty minutes were dedicated to computer software presentation/training as students asked for and were willing to use a specific software tool for the construction of their concept maps. The training time was considered sufficient for computer science postgraduate students to become proficient in constructing concept maps and using them appropriately.

Apart from the utilization of the concept maps as the main assessment tool, concept maps were also used as an instructional tool to present the students' beliefs in the concepts of the subject matter. Following each one of the first two steps of the framework, the instructor composed simple and small concept maps representing the students' beliefs, as these resulted from the corresponding assessment activities. These concept maps were used during the lessons as an instructional tool aiming to (i) encourage the students' participation in the classroom discussions, (ii) create the appropriate circumstances for the students to express their opinions and evaluate other students' arguments, (iii) discuss with the students false beliefs and incomplete understanding, (iv) cultivate the students' critical thinking and reflection by evaluating the statements/beliefs of others, and (v) give feedback to the students about their progress and the process of constructing a concept map. The concept maps, annotated with the discussion-feedback results, were included in the educational material of the course, and were accessible by the students via the EClassroom environment. It is worthwhile mentioning that we avoided using concept maps for presenting the fundamental concepts of the subject matter because we did not want the students to be exposed to any form of "expert's" map during the study. As a result, the concept maps constructed by the students were completely of their own design and construction. 
The remainder of this paper gives a detailed description of the experimental study presenting how each step of the framework was applied, what kind of assessment activities involved in each step, and the evaluation results concerning the effectiveness of the activities in serving the assessment functions under consideration.

\section{Ascertaining the Students' Prior Knowledge: "What the students already know"}

\section{An outline of the assessment activity}

The first activity focused on the first step of the framework aiming to ascertain the students' prior knowledge (Gouli, Gogoulou, \& Grigoriadou, 2003b). More specifically, we focused on the activation of the students' prior knowledge on the fundamental concepts of the subject matter in order to identify unknown concepts, incomplete understanding, and false beliefs of the concepts. The students' prior knowledge was taken into account in the teaching process and was recorded in order to identify, in the subsequent steps, their conceptual changes and their progress.

The assessment activity included assessment items utilizing the free response questions, the questions based on short cases and the concept mapping tasks. The aim of the assessment items, utilizing the free response questions and the questions based on short cases, as a scaffolding framework, was mainly to activate the students' prior knowledge by engaging them in the process of me ntioning concepts, and/or defining concepts and/or relationships between given concepts, and/or comparing concepts. For example, the students were asked (i) to mention up to 10 concepts that are related to the concepts of "Open Education" and/or "Distance Education", (ii) to compare traditional education to distance education, and (iii) to define the fundamental concepts by inferring important/related concepts from the given short case. The aim of the assessment items, utilizing concept mapping tasks, was to identify the students' beliefs (unknown concepts, incomplete understanding and false beliefs) concerning the fundamental concepts of the subject matter and their relationships. The students, taking into account their answers to the free-response questions and the questions based on short cases, had (i) to define the relationships between known concepts such as the relationship between the concepts "Distance Education" and "Traditional Education" by utilizing the "partial recall framework" task, and (ii) to construct three concept maps according to the following:

- for the construction of the first map, concerning the central concept of "Open \& Distance Education", one group of students used the "concept-list" task and added more concepts, if they wished, while the rest constructed the map on their own from scratch and then they enriched their map using the provided list of concepts ("free-construction/concept-list" task). We adopted these two different tasks, as we believed that a scaffolding framework (i) would support the students in their efforts, as the concepts to be represented were "new", and (ii) would prevent floundering and constrain the students" thinking to "productive" directions. Figure 1 presents an example of the maps constructed following the "concept-list" task while Figure 2 presents the two maps constructed by the same student following the "freeconstruction/concept-list" task.

- for the construction of the second and the third concept map, concerning the central concepts of "the Tutor" and "the Educational Material" respectively, all the students worked from

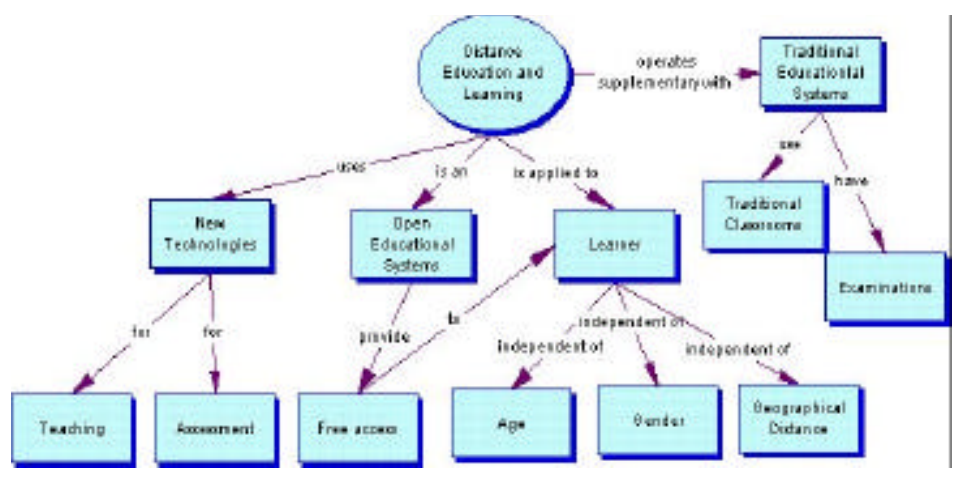

Figure 1: A concept map constructed by a student following the "concept-list" task. 

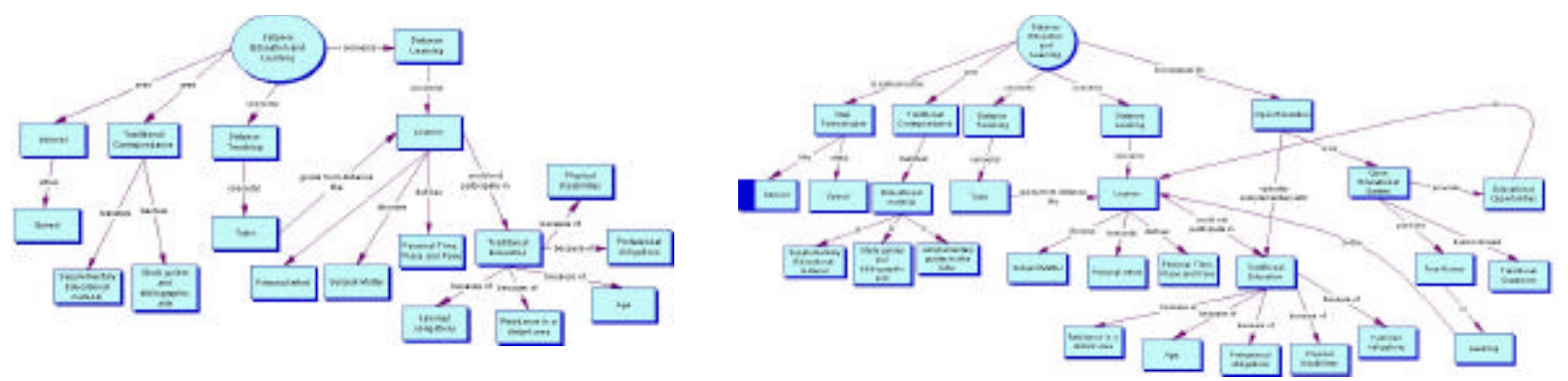

Figure 2: The concept maps constructed by a student following the "free-construction/concept-list" task.

scratch including in their maps as many concepts as they wished ("free-construction" task). We adopted this task, as we believed that the students could work on their own, since they were acquainted with the concepts under consideration in the context of the traditional education. Besides, we aimed to identify the students' beliefs in the relationships between these concepts in the context of the subject matter, since these relationships are changing in the context under consideration.

\section{Experimental results and conclusions}

The analysis of the students' concept maps was rather qualitative focusing on (i) the identification of the students' prior knowledge, and (ii) the effectiveness of the process we followed in order to elicit their prior knowledge.

As far as the features of the maps are concerned, the results showed that a limited number of cross-links and examples appeared, the concept maps did not exceed the four levels of hierarchy, and the number of concepts included was between ten and twenty. Also, in a number of concept maps (46\%), some of the relationships between the concepts were not labelled.

Results concerning “The Students' Prior Knowledge”. Analyzing the students' concept maps, we identified the unknown concepts, their incomplete understanding and their false beliefs. In particular,

- by observing missing concepts, we drew conclusions about unknown concepts e.g. since a limited number of maps included the concepts of "Modular System" and "Open Education", we found that very few students were familiar with these concepts,

- by examining the relations between two or more concepts which did not correctly/fully address the relation of these concepts in the context of the subject matter, we identified the students' incomplete understanding e.g. the proposition, "the tutor teaches the learner", showed that (i) the students were familiar with the concepts of "the tutor" and "the learner", (ii) the definition of the relationship was based on their experience, and (iii) the students were not able to specify the appropriate relationship between these two concepts, as this relationship is different in the context of the subject matter, and

- false beliefs were signalled

$\circ$ by pin-pointing relations between two or more concepts that leads to a clearly false proposition e.g. the proposition "Open Education is an Open Educational System", which is represented on Figure 2, shows a false belief, as the relationship between the concepts is false, and/or

○ by the inclusion of invalid concepts e.g. the concept "Examinations" represented on a number of maps was invalid, as the resulted proposition was false - the use of the concept "Entrance Examinations" is correct, and/or

$\circ$ by a proposition which is not false, but it is characterized as false due to the omission of other relevant propositions. There was a strong trend in false beliefs (e.g. almost all the maps, included only the proposition "Distance Education is carried out through New Technologies" concerning 
the ways that distance education is carried out) resulting from the students' background (i.e. postgraduate students in an Informatics Department) and experience. Therefore, we decided to pay great attention to these concepts and their relationships and to provide clarifications during the teaching process.

Results concerning "The Process". Regarding the process we followed to activate and elicit the students' prior knowledge, the combination of the three assessment tools (i.e. free-response questions, questions based on short cases and concept mapping tasks) proved to be effective as far as the goals of the assessment activity are concerned indicating the supplementary and supportive role of each other during the assessment process (Gouli et al., 2003b). All the three tools supported, at a different degree, the activation and the elicitation of the students' prior knowledge. More specifically, the free response questions gave us the opportunity to have a better gauge of what the students already know, as the majority of whom answered to the questions extensively articulated and reasoned their beliefs, especially to those questions concerning known concepts. The questions based on short cases enabled us to introduce two fundamental concepts to the students and to assess their ability to infer important concepts and to reconsider their previous answers/beliefs. It seems that the short cases enhanced the activation of the students' prior knowledge (55\% of them answered the corresponding questions) in comparison to the corresponding free response questions $(20 \%)$. The scaffolding framework of the short cases helped the students, especially those that were not able to answer to the relevant free response questions, to determine more correctly and precisely the context of the concepts (most of them reconsidered their beliefs).

The scaffolding framework of the free-response questions and the questions based on short cases helped the students during the "free-construction" and the "free-construction/concept-list" tasks. The questions helped them to think of concepts and relationships that they could possibly include in their maps but unfortunately these were fully ignored by the majority of the students when they followed the "conceptlist" task. It seems that providing a list of concepts restricts the students to the given list and prevents them from thinking of any additional concepts and taking into account their answers to the free-response questions and/or the questions based on short cases.

Also, the "concept-list" task, as a scaffolding framework for the construction of the map, was not effective in eliciting the students' prior knowledge. The majority of the students who belonged to this group task tried to represent on their maps almost all the given concepts, sometimes without understanding completely the meaning of the concepts, and paid a little effort to add new concepts on their own. This task led them to construct linear concept maps representing several false beliefs. On the other hand, the tasks of "free-construction/concept-list" and "free-construction" were more effective as these tasks led the students to construct more enriched concept maps (Figure 2). The maps constructed from scratch, revealed that the students brought an awareness of a variety of concepts related to the central concepts. The "free-construction/concept-list" task had the most effective/positive result as it helped the majority of the students to check their thinking, to correct their errors, and to restructure their maps. For example, the concept maps, depicted in Figure 2, concern two maps constructed by the same student, initially from scratch and then by using the list of concepts. The reader may notice that (i) the second concept map has been enriched with more concepts, more cross-links, and one more example, (ii) the structure of the map is more correct than before, and (iii) all the relationships are labelled.

Conclusions. Summarizing the experimental results of this step, we believe that the context of the assessment activity and the use of the concept maps, as the main assessment tool, contributed effectively to "ascertain what the students already know" including faulty and/or incomplete knowledge structures. The ascertainment of the students' prior knowledge helped us to specify the starting point of the teaching process and the subject areas that needed great attention and guidance during the instruction. Regarding the effectiveness of the process we followed to activate and elicit the students' prior knowledge, we concluded that (i) the assessment tools that were utilised and combined, proved to be effective as far as the goals of the assessment activity are concerned, indicating the supplementary and the supportive 
role of each other, (ii) the scaffolding framework of the free-response questions and the questions based on short cases helped the students in activating their knowledge, (iii) the students' answers to the freeresponse questions and the questions based on short cases were taken into account during the "freeconstruction" and the "free-construction/concept-list" tasks while they were ignored during the "concept-list" task by the majority of the students, (iv) the "concept-list" task was not effective for eliciting and investigating the students' prior knowledge as it prevented them from focusing on what they really know, and (v) the most effective process was the "free-construction/concept-list" task as the students had the opportunity to represent their knowledge on their own and then to enrich and revise their representations on the basis of the scaffolding framework. The students' opinion about the assessment activity, resulting from the final evaluation of the experimental study, indicates their preference to a scaffolding framework in order to be supported during their work.

\section{Promoting Knowledge Construction \& Identifying Conceptual Changes: "How students act in playing a role"}

\section{An outline of the assessment activity}

In the context of the second step of the framework, we developed a collaborative (a paired work) assessment activity, where the students played the role of the tutor in ODL and assessed a concept map concerning the central concept of "Open \& Distance Education". The concept map concerned the coursework of a (fictional) learner and included concepts that had already been taught (e.g. the concept of ODL, the role of the tutor in ODL, the characteristics of the educational material suitable for ODL purposes). However, evaluation methods and scoring schemes applied to concept mapping had not been explicitly mentioned during the lessons.

The assessment activity was based on the idea of goal-based scenarios (Schank et al., 1999) addressing an aspect of the tutor's role. According to the scenario of the activity, the students played the role of a tutor in a course entitled "Distance Education and Learning" offered exclusively by distance. The mission of the students was to assess the coursework (i.e. the concept map) of a (fictional) learner. The scenario operations, comprising all of the activities the students had to do in order to work towards the mission goal, included (a) studying the learner's coursework, (b) determining the criteria and the score scheme for the assessment, (c) assessing the coursework and reasoning their evaluation, (d) writing a letter to the learner concerning his/her coursework assessment.

The scenario operations are closely related to both the mission and the assessment goals. In the context of the assessment activity, the scenario operations were serving the following goals: (i) to investigate the students' beliefs in the concepts of the subject matter and their conceptual changes (resulting from (c) and (d) scenario operations), (ii) to engage the students in an active knowledge construction by performing operations such as understanding and evaluating the concepts and their relationships that are represented, defining new concepts, relationships and cross-links, and/or restructuring the concepts (resulting from (b), (c) and (d) scenario operations), and (iii) to engage the students in the role of the tutor in an ODL educational system by taking into account his/her advisory, mediatory, and instructive role (resulting from (b), (c) and (d) scenario operations). Apart from the aforementioned assessment goals, we sought the active involvement of the students and the promotion of collaborative learning by encouraging them to work in pairs and help each other. We also stimulated the students to develop reflection, revision and critical thinking through the assessment of a (fictional) learner's coursework by undertaking the role of the assessor and the feedback provider.

The (fictional) learner's concept map was constructed and structured taking into account (i) the students' beliefs as these were recorded in the previous step, (ii) the concepts that had already been taught, and (iii) the discussions-feedback that had taken place in the classroom. The concept map consisted of thirty concepts, structured in four levels of hierarchy with fourteen cross-links. The concept map, in addition 
to the valid concepts, links and cross-links, also included (i) invalid links between concepts in order to investigate the hypothesis (a) that the students confuse the relationships between concepts that are difficult and/or the students confuse the relationships between concepts for which they had false prior knowledge, (b) that the students confuse the relationships between familiar concepts, as their meaning in the context of the subject matter is being transformed, and (ii) incompleteness of concepts, links and cross-links in order to investigate the hypothesis that the students, through the context of the assessment activity, may develop high level cognitive skills such as analyzing, synthesizing, organizing and/or restructuring of information.

In the following, we present the experimental results, concerning only the first and the second assessment goal since the results concerning the third goal is beyond the scope of the paper as they are related exclusively with the subject matter. (They are presented and discussed in detail in Grigoriadou Gouli, and Gogoulou (2003)).

\section{Experimental results and conclusions}

The qualitative analysis of the students' responses focused on the examples that they had used in order to reason their evaluation, the letter that they had written to the (fictional) learner in order to give him/her comments and feedback and the evaluation criteria that they had determined.

Results concerning “The Students' beliefs and their conceptual changes". Based on the students' responses, concerning the reasoning of their evaluation and the feedback that they included in the letter, we found that the students encountered learning difficulties when they tried to reason the relationships between fundamental concepts of the subject matter such as "Distance Education - Open Education", "Educational Material - Modular System" and "Tutor - Learner". The learning difficulties are possibly due to the following reasons:

(i) the students were unfamiliar with some concepts such as the concept of the "Modular System",

(ii) some concepts were difficult to be defined and/or to be discriminated from other concepts such as the concept of the "Open Education",

(iii) the students' false prior knowledge, concerning specific concepts, prevented them from determi ning correctly the context of these concepts e.g. the students considered the concepts of the "Distance Education" and the "Open Education" as similar,

(iv) their experience/profile played an important role and prevented them from determining correctly the context of some concepts e.g. this becomes obvious when they reasoned the relationships between the fundamental concepts of the subject matter and the concept of the "New Technologies",

(v) although some concepts were familiar to the students, their context in the subject matter is transformed and/or enhanced e.g. the relationship between the concepts of the "Educational material" and the "Tutor".

In Figure 3, we present the percentage of the students' correct current beliefs concerning ten specific relationships between fundamental concepts of the subject matter. These relationships have been coded, such as A represents the relationship between the concepts "Distance Education" and "Open Education", B represents the relationship between the concepts "Distance Education" and "Modular System", D represents the relationship between the concepts "Educational Material" and "Modular System", H represents the relationship between the concepts

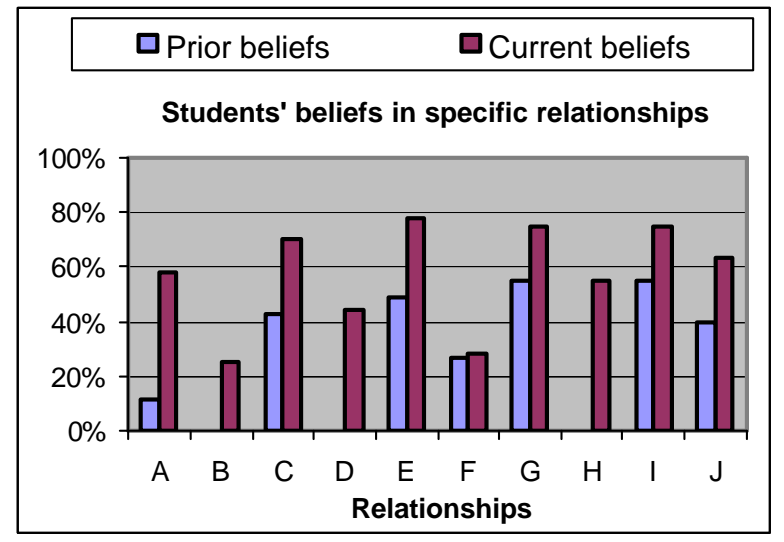

Figure 3: The percentage of the students' correct prior and correct current beliefs concerning relationships between fundamental concepts of the subject matter. 
"The Tutor" and "The Subject Matter" and so on. Also, in Figure 3, the percentage of the students' correct prior beliefs is presented, concerning the same relationships. The percentage of the students' prior beliefs concerning the relationships $\mathrm{B}, \mathrm{D}$ and $\mathrm{H}$ is equal to zero as these relationships concern concepts that were unfamiliar to the students (i.e. relationships B and D concern the concept of "Modular System"), and/or concern relationships that have not been inspected in the previous step (i.e. relationship $\mathrm{H})$. The reader may notice that the students revised most of their beliefs as the learning progressed. An interesting point, represented on the diagram, concerns the students' beliefs in the relationship coded as F. This belief refers to the relationship between the concepts of the "Tutor" and the "New Technologies". It seems, in this case, that the students' experience and profile prevented them from revising their belief in contrast to other similar cases (e.g. relationships $\mathrm{C}$ and E concerning the role of "New technologies" in Distance Education).

Results concerning “The Context of the Assessment Activity". As far as the evaluation criteria for the assessment of the concept map are concerned, we found that (i) the majority of the students (approximately 80\%) determined criteria according to their experience and their knowledge of how to construct a concept map, and (ii) a limited number of students tried to find and apply criteria from bibliography (Novak \& Gowin, 1984) and/or from Internet resources. In Figure 4, the most indicative criteria that were determined by the students are presented. The reader may notice that the majority of the students (96\%) focused their attention on the criterion concerning the appropriateness/correctness of the relationships between the concepts. Although, a number of students had also determined criteria concerning the completeness of the concepts (79\% of students), the completeness of the relationships (43\% of students), the existence of cross-links (39\% of students) and examples (29\% of students), these criteria were used for the assessment of the concept map to a low degree. More specifically, studying the students' letters, we noticed that a minimum number of comments/feedback concerned the enrichment of the concept map (i) with more concepts e.g. the characteristics of the Distance Education $(55 \%)$, the characteristics of the educational material (18\%), (ii) with more links e.g. between the concepts of the "Tutor" and "Learner" (32\%), (iii) with more cross-links e.g. between the concepts of the "Learner", the "Tutor" and the "Geographical Distance", and (iv) with more examples, clarifying the meaning of some concepts (11\%).

The aforementioned analysis shows that a small number of students performed high level cognitive operations such as analysis of the repre-

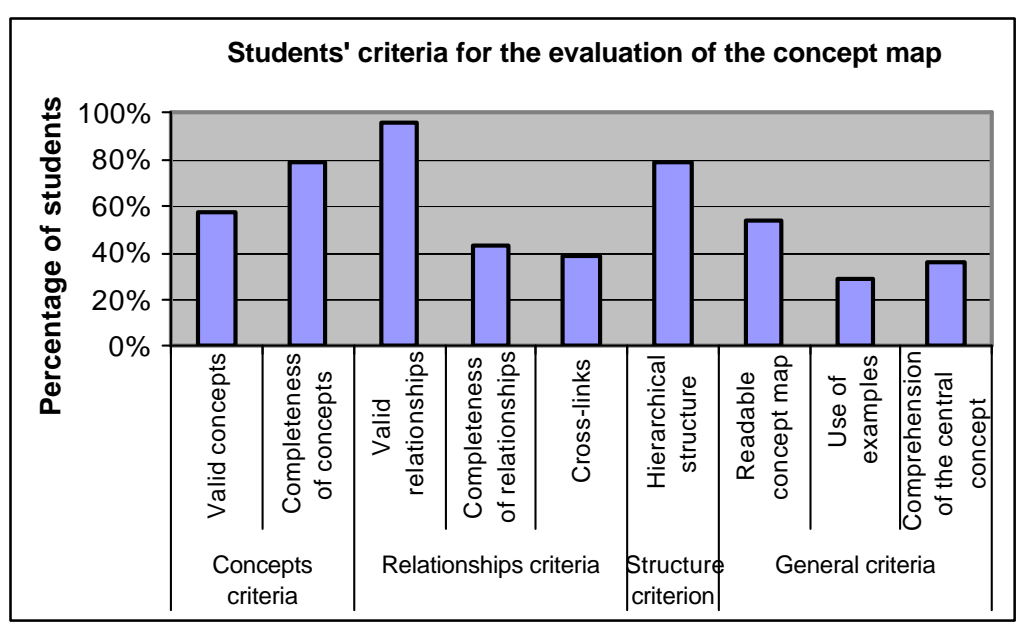

Figure 4: The most indicative assessment criteria given by the students. sented concepts, synthesis, and/or reorganization of the given and the new concepts. This is maybe due to the following reasons: (i) the use of a concept map, constructed and structured by the teacher, restricted the students to the examination of the validity of the existent relationships and prevented them from achieving higher levels of cognitive performance, and (ii) the students' lack of experience in assessing concept maps. Perhaps, a form of feedback (e.g. through case studies that pertain to similar operations and/or experiences) may support students in their efforts, as a scaffold to achieve higher levels of cognitive performance.

The students' opinion about the context of the activity, resulting from the final evaluation of the experimental study, is positive. Indicative students' comments were: "During the assessment process, I won- 
dered about concepts and relationships that I had never thought before", "The assessment of a learner's coursework increases your responsibility for accurate and valid evaluation", "During the assessment process, I had the sense of insecurity about what was correct and what was false", "I found it interesting and quite helpful in understanding the meanings of the concepts and their interrelationships", "Through the context of the assessment activity, I understood my errors and the process helped me to determine criteria and rules towards the right approach", "It was a useful process as it gave me the opportunity to discover my errors and to try to avoid them again", "Playing the role of the tutor, I realized how teachers evaluate our coursework and what they expect from us".

Conclusions. Summarizing the experimental results of this step, we believe that the context of the assessment activity and the use of concepts maps enabled the identification and the assessment of the students' progressive conceptual changes concerning the fundamental concepts of the subject matter. More specifically, we found that the majority of the students revised most of their beliefs and enriched their knowledge structure but they still encountered difficulties concerning relationships between fundamental concepts of the subject matter that (i) were unfamiliar and difficult to be defined and/or discriminated from other concepts, and/or (ii) the students had false prior knowledge, and/or (iii) were familiar to the students but their meaning is different in the context of the subject matter. The context of the assessment activity contributed to the achievement of cognitive performance concerning mainly the Comprehension level, while higher levels of cognitive performance was achieved to a low degree. The incorporation of the concept map evaluation in an authentic context activated the students and helped them to develop skills of reasoned judgment, reflection, revision and critical thinking. Future studies may be conducted in order to examine possible scaffolding aids (e.g. case studies), which may help the students to cultivate higher levels of cognitive processes within the context of the assessment activity.

\section{Assessing Knowledge Construction: “How the students' knowledge is finally constructed"}

\section{An outline of the assessment activity}

The last activity of the study, concerning the third step of the AssessToLearn framework, aims to (i) facilitate the teachers in effectively answering questions like "What is on the students' mind?", "What are the conceptual changes? - Is there any growth in the students' conceptual understanding?", and (ii) support the students in refining their knowledge and developing a viable mental model.

The assessment activity included an assignment focused on specific subject-matter topics, a concept mapping task and an evaluation task. The concept mapping task engaged the students in constructing, on their own from scratch, a concept map concerning the central concept of "Open \& Distance Education" and representing their beliefs in the taught concepts. Upon the completion of the concept mapping task, the students had to act as evaluators of their own work (promoting self assessment) by determining criteria, scoring their map for each criterion and reasoning their evaluation. The students could use the criteria and the scoring scheme that they had determined in the context of the activity carried out in the second step, and proceed with any revisions if necessary. The inclusion of such an evaluation task aimed to promote the development of self-regulation skills and to make the students more responsible for their own learning. In the following, we present the experimental results, concerning the concept mapping task and the evaluation task as the assignment results concern specific aspects of the subject matter, which are beyond the scope of the paper.

\section{Experimental results and conclusions}

Evaluation scheme. The concept maps constructed by the students from scratch, were quite diverse. For their interpretation, we defined a conceptual structure of the subject matter including (i) fundamental concepts, (ii) useful concepts, and (iii) related concepts. The fundamental and the useful concepts consti- 
tute a pre-specified list of concepts used for evaluating the completeness of the concepts represented on the students' concept maps. The fundamental concepts concern the basic concepts of the subject matter while the useful concepts concern the concepts that analyze and/or clarify the fundamental concepts. We consider as related concept each concept of the students' concept maps that is not included in the above categories, but it may be represented on the maps (i.e. its meaning is correct and it is related to the subject matter and the central concept of the map).

The following criteria were determined taking into account the conceptual structure of the subject matter and the features of the concept map:

(i) The Comprehensiveness of the Subject Matter (CSM) resulting from the sub-criteria of :

- the Completeness of the fundamental concepts (Cfc) (i.e. the presence of valid fundamental concepts) and

- the Completeness of Relationships among the fundamental concepts (CRfc) (i.e. the presence of valid links and cross-links among the fundamental concepts).

Different weights were assigned to the above sub-criteria, expressing their relative importance with respect to the criterion under consideration.

(ii) The Completeness of the Concepts' represented on the map (CC) (i.e. the presence of valid fundamental concepts, useful concepts and related concepts).

(iii) The Levels of Hierarchy on the map (LH) (i.e. valid levels of hierarchy).

(iv) The Complexity of the map $(\mathrm{Cm})$ resulting from combining and assigning different weights to the features of the concept maps, concerning the number of the valid cross-links among all the concepts represented on the map and the valid levels of hierarchy.

A qualitative scoring scheme was adopted for each of the above criteria classifying the students' performance to one of the following categories \{Insufficient (Ins), Rather Insufficient (RIns), Average (Ave), Rather Sufficient (RSuf), Sufficient (Suf)\}. The scoring scheme for each criterion was experimentally set providing better results in differentiating the students' performance.

Experimental results. In the following, we present the experimental results concerning (i) the students' performance according to the evaluation scheme we set, (ii) the students' conceptual changes in comparison to the results of the first and the second step, and (iii) the students' results concerning the evaluation task. Figures 5 and 6 represent two concept maps characterized as "Suf" in almost all of the criteria. The reader may clearly notice the large number of concepts included in the maps, the large number of links between concepts, a considerable number of cross-links, a number of examples and the hierarchical structure of the concept maps. These concept maps were constructed by the same students, who developed the maps depicted in Figures 1 and 2 respectively.

Experimental results concerning "The Students' Performance”. The evaluation of the students' concept maps, according to the criteria that were determined, revealed the following:

- The distribution of the students' performance according to the Cfc subcriterion, as it is illustrated in Figure 7 , shows that the performance level of all the students on this subcriterion is above average. The reader may notice that the majority of the students included almost all

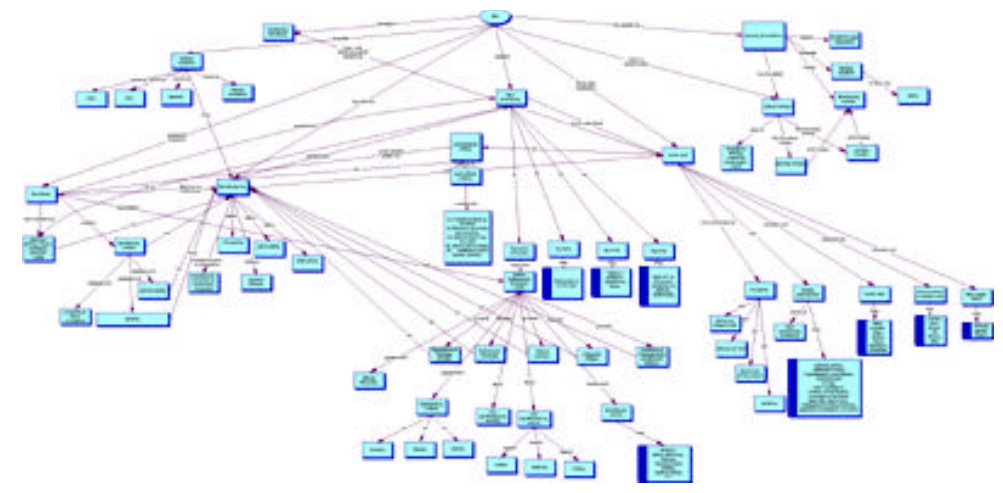

Figure 5: A concept map submitted at the end of the course by the student who constructed, at the beginning of the course, the concept map illustrated in Figure 1. 
the fundamental concepts in their maps (the performance of $79 \%$ of the students characterized as "Suf" and "RSuf"). This suggests that all the students were quite aware of the fundamental concepts of the subject matter. On the other hand, the students' performance according to the sub-criterion of CRfc is not so high i.e. the performance of $68 \%$ of the students is above the average. It seems that, although the majority of the students assimilated the fundamental concepts of the subject matter, they encountered difficulties in relating the fundamental concepts and/or establishing correct relationships among them. In order to determine the weights of the sub-criteria and moreover to evaluate the students' comprehensiveness level of the subject matter, we were based on their ability to relate the fundamental concepts and to establish appropriate relationships (key-point). To this end, greater weight was assigned to the CRfc sub-criterion (i.e. 0.6 to the CRfc and 0.4 to the $\mathrm{Cfc})$. This key-point enabled us to differentiate the students and facilitated the drawing of comparisons concerning the performance of the students and their ability to relate the fundamental concepts of the subject matter. The distribution of the students' performance according to the CSM criterion, as it is illustrated in Figure 7, shows that the performance level of the majority of the students was above average (91\%).

- The distribution of the students' performance according to the $\mathrm{CC}$ criterion is illustrated in Figure 8. A considerable number of students (74\%) included in their maps a significant amount of fundame ntal and useful concepts as well as a number of related concepts. Therefore, their performance is characterized above average. The rest of the students $(26 \%)$ included only fundamental concepts, showing difficulties in analyzing the domain knowledge in a greater depth and/or breadth.

- The distribution of the students' performance according to the LH criterion is illustrated in Figure 8. The results were characterized as average $(50 \%)$ in their majority. This suggests that the students encountered difficulties in analyzing the concepts at various levels of detail (the performance of 59\% of students is characterized as "Ave" and "RIns" according to the criterion of the LH). 
- As far as the criterion of the $\mathrm{Cm}$ is concerned, only $33 \%$ of the students' performance (Figure 8) may be characterized above average. In order to determine the weights of the number of valid cross-links and the valid levels of hierarchy and moreover to evaluate the students' performance according to the criterion of the $\mathrm{Cm}$, we were based on their ability to relate concepts and construct a coherent concept map (key-point). To this end, greater weight was assigned to the number of valid cross-links (i.e. 0.6 to the number of valid cross-links and 0.4 to the valid levels of hierarchy). This key-point enabled us to differentiate the students according to their ability to relate different chunks of information.

Experimental results concerning "The Students' Conceptual Changes". Regarding the question "What are the conceptual changes? - Is there any growth in the students' conceptual understanding?", we examined the students' beliefs concerning the ten particular relationships between the fundamental concepts of the subject matter as they were presented in the second step (Sub-paragraph: The Students' beliefs and their conceptual changes in the paragraph: Promoting Knowledge Construction \& Identifying Conceptual Changes: "How students act in playing a role" and Figure 3). In Figure 9, the percentage of the students' final beliefs (i.e. correct beliefs in the relationships under consideration) is presented in comparison to their initial (prior) beliefs (first step) and their revised beliefs (second step). The reader may notice that the students revised successfully most of their beliefs at the end of the teaching and the learning process. The lower percentages of correct beliefs concern the relationships B (65\%), E (84\%) and F (88\%). This is probably due to the fact that the relationship B concerns concepts which were "new" to the students at the beginning of the course while $\mathrm{E}$ and $\mathrm{F}$ represent relationships between concepts which were familiar to the students and their experience and profile prevented them from rethinking and revising their opinion.

Experimental Results concerning the "Evaluation Task". The students' responses concerning the evaluation task were quite diverse. The diversity is due to the criteria that the students set, the scoring scheme that they applied, their reasoning for the evaluation judgement and the evaluation itself. In Figure 10 the students' and the teacher's final evaluation results are presented for ten indicative cases. Due to the diversity of the criteria that were determined by the students, we present only the evaluation results concerning the criteria that were common. Moreover, in order to have a unified scoring scheme, the students' scoring scheme was adapted appropriately. 


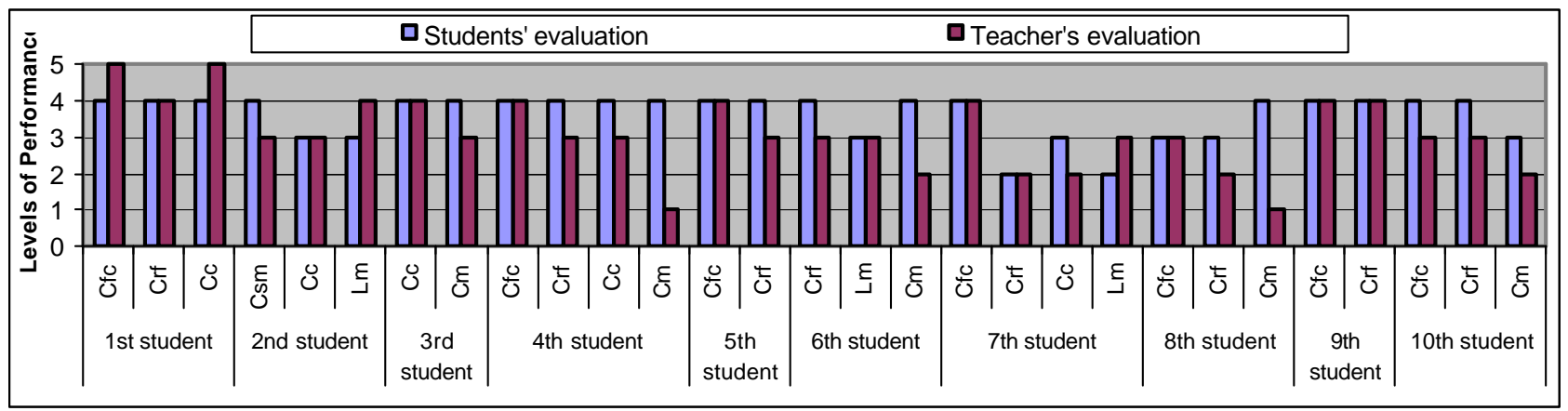

Figure 10: The students' and the teacher's evaluation according to the common sub-criteria of the Cfc and the Crf as well as the common criteria of the CSM, the Cc, the $\mathrm{LH}$ and the $\mathrm{Cm}$. The levels of performance 1 till 5 represent the levels of the qualitative scheme i.e. 1 corresponds to "Ins", 2 corresponds to "RIns", 3 corresponds to "Ave", 4 corresponds to "RSuf" and 5 corresponds to "Suf".

Analyzing the results illustrated in Figure 10, the reader may notice the following: (i) the teacher's and the students' evaluation coincided in some cases, e.g. the case of the $9^{\text {th }}$ student - showing that some students developed high level skills such as critical thinking, reflection and self-regulation, (ii) the criteria, that in most cases the students' and the teacher's evaluation coincided, concerned the Cfc subcriterion and/or the CC criterion - this suggests that a number of students were aware of the fundamental concepts and/or the useful concepts of the subject matter, (iii) the criteria, that in most cases the students' and the teacher's evaluation were different and especially the students' evaluation was higher than the teacher's evaluation, concerned the CRfc sub-criterion and the $\mathrm{Cm}$ criterion - this is probably due to the students' low performance according to these two criteria, (iv) some students, especially the very good ones, tended to underrate themselves in almost all of the evaluation process as in case of the $1^{\text {st }}$ student, and (v) some students, especially the weaker students, tended to overrate themselves in almost all of the evaluation process as in case of the $4^{\text {th }}, 6^{\text {th }}, 8^{\text {th }}$, and $10^{\text {th }}$ students.

Conclusions. Summarizing the experimental results of this step, we believe that the context of the assessment activity and the use of the concepts maps enabled the draw of inferences about the students' overall understanding of the subject matter, the detection of changes in the students' conceptual understanding, the identification of differences in the students' abilities and the determination of key-points that may be used in order to differentiate the students' knowledge level concerning the subject matter. More specifically, we found that the students were aware of the fundamental concepts of the subject matter but their performance was quite diverse in analyzing/organizing concepts at various levels of detail/hierarchy and in relating/connecting different chunks of information among various topics of the subject matter. Through the concept mapping task, we were able to easily and precisely detect changes in the students' conceptual understanding in comparison to their initial and intermediate conceptions. Also, the evaluation task in the context of the assessment activity, gave the students the chance to become active participants in their own learning and to refine further their knowledge by evaluating their own work. It is worthwhile mentioning that the amount of time needed to identify the students' performance according to the criteria was comparable to the time needed in order to grade a "traditional final exam". As, Ruiz-Primo and Shavelson reported in (1996), scoring a concept map, when scoring/evaluation criteria have been established, requires only 3 to 10 minutes, depending on the complexity of the map. 


\section{Concluding Remarks \& Future Plans}

Regarding educational assessment as an essential part of the teaching and the learning processes, we propose a coherent and integrated framework, in order to serve a variety of assessment functions. The AssessToLearn framework, comprising a three-step process, provides a basis for the design of assessment activities utilizing concept maps as the main assessment tool. Moreover, the AssessToLearn framework constitutes the basis for the development of a web-based adaptive assessment environment, referred to as PASS, which aims to support the assessment process in the context of the framework and provide adaptive capabilities. The proposed framework was experimentally evaluated in a real classroom environment in the context of a study that we conducted. The assessment activities, developed on the basis of the proposed framework, served specific assessment functions in the context of the postgraduate course of "Distance Education and Learning". The experimental results are encouraging, indicating the effectiveness of the assessment activities and subsequently the effectiveness of the framework in serving the specific assessment functions. The coherency and the integration of the three steps of the proposed framework seem to serve the educational assessment process effectively and further support the teaching and the learning processes.

The experimental study, as it was conducted in a real classroom environment and within the daily educational practice, revealed that the assessment process, which was followed, may be applied in any educational setting giving positive results as far as the accomplishment of the assessment functions is concerned. More specifically, the assessment activities, designed on the basis of the framework, and the utilization of the concept maps as the main tool of the assessment toolbox contributed effectively (i) to "ascertain what the students already know" including faulty and/or incomplete knowledge structures, (ii) to identify the students' unknown concepts, incomplete understanding and false beliefs, (iii) to assess the students' progressive conceptual changes concerning the fundamental concepts of the subject matter, (iv) to identify the differences in the students' abilities, and (v) to determine the key-points that may be used in order to differentiate the students' knowledge level concerning the subject matter. It seems that the application of the proposed assessment framework enhances learning and results in students shifting from memorization to meaningful learning. Despite the encouraging results, the successful application of the framework depends on a number of factors such as (i) the adequate time and effort that the teachers have to devote in order to design the assessment process (e.g. determine the assessment goals and outcomes, the assessment functions, the ordering of the steps, the forms of the assessment to be followed in each step, select/combine the appropriate assessment tools), to design and develop the appropriate assessment activities, to specify and provide the appropriate feedback, (ii) the possibility that the teachers have in changing their instruction, and/or their teaching strategies and/or sometimes the curriculum in order to integrate the assessment process with learning and instruction, and (iii) the possibility of changing the daily educational practice from "teaching/learning to the test" to "learning how to learn". Also, there is a need to create the appropriate circumstances for the students to become active participants and self-regulated in the assessment and the learning process and to accept the "new" educational setting.

During the current spring-semester (i.e. of the academic year 2002-2003), we applied again the proposed assessment framework in the context of the same postgraduate course in order to examine more closely some issues, implied by the assessment framework such as (i) the utilization of other assessment tools apart from the concept mapping tasks, (ii) the possibility of making adaptive and effective combinations of the various alternative assessment tools, and (iii) the function of the collaborative assessment and the peer-assessment and their influence on the students' performance and knowledge construction. So far, the results are positive providing useful information as far as the combination of the various assessment tools and the support of other forms of assessment are concerned. Upon the completion of the PASS environment, which is one of our near future plans, we plan to carry out a number of experimental studies in order to (i) examine various issues such as the grouping of students in order to work on collaborative assessment activities and to assess their peers' work, and the provision of the appropriate forms of feed- 
back during the assessment process according to the students' preferences and needs, and (ii) apply and evaluate the assessment framework in the context of other subject matters.

\section{Acknowledgment}

The authors would like to thank all the students who participated in the study.

\section{References}

Ausubel, D., Novak, J., \& Hanesian, H. (1978). Educational psychology: A cognitive view (2 ${ }^{\text {nd }}$ Ed.). New York: Holt, Rinehart \& Winston.

Bransford, T., Brown, A. \& Cocking, R. (1999). (Eds). How people learn: Brain, mind, experience and school. Knowing what students know: The Science and Design of Educational Assessment. National Academy of Sciences. Washington DC: National Academy Press.

Chang, K., Chen, S-F., \& Sung, T. (2001). Concept mapping system with scaffolding and guided learning. Journal of Computer Assisted Learning, 17 (1), 21-33.

Chi, M.T.H. (1996). Constructing self-explanations and scaffolded explanations in tutoring. Applied Cognitive Psychology, $10, \mathrm{~S} 33-\mathrm{S} 49$.

Chiu, C-H, Huang, C-C., \& Chang, W-T. (2000). The evaluation and influence of interaction in network supported collaborative concept mapping. Computers \& Education, 34 (1), 17-25.

Edmondson, K. (2000). Assessing science understanding through concept maps. In J. Mintzes, J. Wandersee, \& J. Novak (Eds.), Assessing Science Understanding: A Human Constructivist View. (pp. 15-40). Educational Psychology Series. San Diego, CA: Academic Press.

Fisher, K. (2000). SemNet software as an assessment tool. In J. Mintzes, J. Wandersee, \& J. Novak (Eds.), Assessing Science Understanding: A Human Constructivist View. (pp. 197-221). Educational Psychology Series. San Diego, CA:Academic Press.

Fisher, K., Faletti, J., Patterson, H., Thornton, R., Lipson, J., \& Spring, C. (1990). Computer-based concept mapping. Journal of College Science Teaching, 19 (6), 347-352.

Fisher, K., Wandersee, J., \& Wideman, G. (2000). Enhancing cognitive skills for meaningful understanding of domain specific knowledge. American Association for the Advancement of Science. Retrieved February 2002 from the World Wide Web http://public.sdsu.edu/CRMSE/Fisher-one.com

Gogoulou, A., Gouli, E., Grigoriadou, M., \& Samarakou, M. (2003). Supporting collaboration and adaptation in a CSCL environment. In the $3^{{ }^{t}}$ IEEE International Conference on Advanced Learning Technologies (p. 470), Athens, Greece.

Gouli, E., Gogoulou, A., Grigoriadou, M., \& Samarakou, M. (2003a). Towards the development of an adaptive communication tool promoting cognitive and communication skills. In Proceedings of the PEG 2003 Conference, St. Petersburg, Russia.

Gouli, E., Gogoulou, A., \& Grigoriadou, M. (2003b). Ascertaining what the students already know. In Proceedings of the ED-MEDIA 2003, World Conference on Educational Multimedia, Hypermedia \& Telecommunications Conference, Honolulu, Hawaii, USA.

Gouli, E., Papanikolaou, K. \& Grigoriadou, M. (2002). Personalizing assessment in adaptive educational hypermedia systems. In P. De Bra, P. Brusilovsky \& R. Conejo (Eds), Adaptive Hypermedia and Adaptive Web-based Systems, Second International Conference, LNCS 2346, pp. 153-163, Springer-Verlag, Berlin.

Grigoriadou, M., Gouli, E., \& Gogoulou, A. (2003). The use of concept maps in the learning process of "Distance Education". In Proceedings of the 2nd Hellenic Conference, on Open and Distance Education (pp. 371-381), Patras, Greece.

Horton, P., McConney, A., Gallo, M., Woods, A., Senn, G., \& Hamelin, D. (1993). An investigation of the effectiveness of concept mapping as an instructional tool. Science Education, 77 (1), 95-111.

Hsieh, I. \& O’Neil, H. F., Jr. (2002). Types of feedback in a computer-based collaborative problem-solving group task. Computers in Human Behavior, 18, 699-715.

Jonassen, D., Reeves, T., Hong, N., Harvey, D., \& Peters, K. (1997). Concept mapping as cognitive learning and assessment tools. Journal of Interactive Learning Research , 8 (3/4), 289-308. 
Kommers, P., Grabinger, S., \& Dunlap, J. (1996). Hypermedia learning environments. Instructional design and integration. Lawrence Erlbaum Associates.

Kordaki, M. \& Avouris, N. (2002). Essential issues for the design of open learning environments emerged from a field evaluation study. Journal for Applications in Information Technology, 1 (1), Special Issue for e-learning. Retrieved April 2003 from the World Wide Web http://www.japit.org

Markham, K., Mintzes J., \& Jones, G. (1994). The concept map as a research and evaluation tool: Further evidence of validity. Journal of Research in Science Teaching, 31 (1), 91-101.

Mintzes, J., Wandersee, J., \& Novak, J. (2000). Assessing science understanding: A human constructivist view. Educational Psychology Series, Academic Press.

Novak, J. (1990). Concept mapping: A useful tool for science education. Journal of Research in Science Teaching, 27(10), 937-949.

Novak, J. (1998). Learning, creating and using knowledge: Concept maps as facilitative tools in schools and corporations. Mahwah, NJ: Lawrence Erlbaum Associates.

Novak, J. \& Gowin, D. (1984). Learning how to learn. Cambridge, UK: Cambridge University Press.

Novak, J. \& Musonda, D. (1991). A twelve-year longitudinal study of science concept learning. American Educational Research Journal, 28 (1), 117-153.

Pearsall, N., Skipper, J., \& Mintzes, J. (1997). Knowledge restructuring in the life sciences: A longitudinal study of conceptual change in biology. Science Education, 81 (2), 193-215.

Pellegrino, J., Chudowsky, N., \& Glaser, R. (2001). (eds). Knowing what students know: The science and design of educational assessment. National Academy of Sciences. Washington DC: National Academy Press.

Rice, D., Ryan, J., \& Samson, S. (1998). Using concept maps to assess student learning in the science classroom: Must different methods compete? Journal of Research in Science Teaching, 35 (10), 1103-1127.

Ruiz-Primo, M., \& Shavelson, R. (1996). Problems and issues in the use of concept maps in science assessment. Journal of Research in Science Teaching, 33 (6), 569-600.

Ruiz-Primo, M., Shavelson, R., \& Schultz, S. (1997). On the validity of concept-map-based assessment interpretations: An experimental testing the assumption of hierarchical concept maps in science. CSE Technical Report 455: CRESST University of California, CA.

Segers, M., Dochy, F. \& De Corte, E. (1999). Assessment practices and students' knowledge profiles in a problem-based curriculum. Learning Environments Research, 2, 191-213.

Schank R., Berman T., \& Macpherson K. (1999). Learning by doing. In Charles M. Reigeluth (Eds.), Instructional-design Theories and Models, A New Paradigm of Instructional Theory. (Volume II, pp.161-184). Lawrence Erlbaum Associates, Inc.

Shavelson, R. J., Lang, H. \& Lewin, B. (1994). On concept maps as potential "authentic" assessments in science. CSE Technical Report 388: CRESST University of Santa Barbara, CA.

Trowbridge, J., \& Wandersee, J. (1998). Theory-driven graphic organizers. In J. Mintzes, J. Wandersee, \& J. Novak (Eds.), Teaching science for understanding: A human constructivist view. (pp. 95-131). San Diego, CA: Academic Press.

Tsai, C., Lin, S., \& Yuan, S. (2001). Students' use of web-based concept map testing and strategies for learning. Journal of Computer Assisted Learning, 17(1), 72-84.

Vosniadou, S. (2001). How children learn. International Academy of Education. Educational Practices Series, 7. Retrieved September 2002 from http://www.ibe.unesco.org/International/Publications/EducationalPractices/prachome.htm 

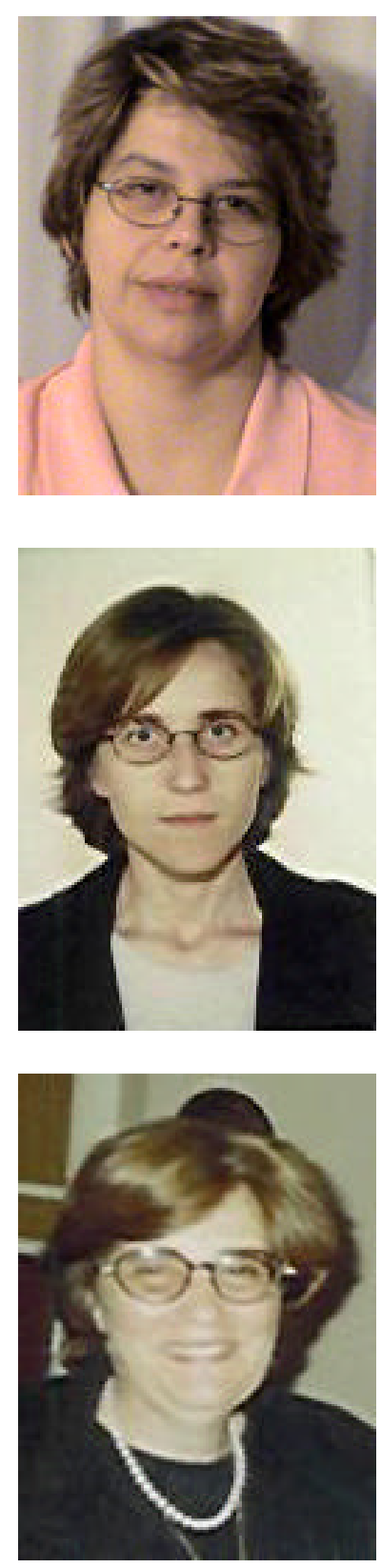

\section{Biographies}

Evangelia Gouli is a PhD Student in the area of Distance and Open Education at the Department of Informatics and Telecommunications of the University of Athens, Greece. Her research interests are in the areas of adaptive hypermedia, collaborative learning, intelligent learning environments on the web, student modeling and assessment in the learning process. Her $\mathrm{PhD}$ research is focused on the development of a web-based adaptive learning environment supporting students' assessment and providing personalized support and feedback.

Agoritsa Gogoulou is a PhD Student in the area of Didactics of Informatics at the Department of Informatics and Telecommunications of the University of Athens, Greece. Her research interests are in the areas of Didactics of Informatics, intelligent learning environments, collaborative learning environments, student modeling and student assessment. Her $\mathrm{PhD}$ research is focused on the development of a learning environment for the instruction and assessment in Informatics.

Maria Grigoriadou is an Associate Professor at the Department of Informatics and Telecommunications of the University of Athens, Greece. Her research interests are in the area of multimedia interactive learning environments, intelligent tutoring systems (student model, instructional strategies, diagnosis), computer science education, distance learning based on Internet, and natural language processing (tools, morphological and syntactic analysis). 